\title{
Phosphate control in dialysis
}

This article was published in the following Dove Press journal: International Journal of Nephrology and Renovascular Disease 7 October 2013

Number of times this article has been viewed

\author{
Adamasco Cupisti ${ }^{1}$ \\ Maurizio Gallieni² \\ Maria Antonietta Rizzo² \\ Stefania Caria ${ }^{3}$ \\ Mario Meola ${ }^{4}$ \\ Piergiorgio Bolasco ${ }^{3}$ \\ 'Department of Clinical and \\ Experimental Medicine, University \\ of Pisa, Pisa, Italy; ${ }^{2} \mathrm{Nephrology}$ and \\ Dialysis Unit, San Carlo Borromeo \\ Hospital, Milan, Italy; ${ }^{3}$ Territorial \\ Department of Nephrology and \\ Dialysis, ASL Cagliari, Italy; ${ }^{4}$ Sant'Anna \\ School of Advanced Studies, \\ University of Pisa, Pisa, Italy
}

Abstract: Prevention and correction of hyperphosphatemia is a major goal of chronic kidney disease-mineral and bone disorder (CKD-MBD) management, achievable through avoidance of a positive phosphate balance. To this aim, optimal dialysis removal, careful use of phosphate binders, and dietary phosphate control are needed to optimize the control of phosphate balance in well-nourished patients on a standard three-times-a-week hemodialysis schedule. Using a mixed diffusive-convective hemodialysis tecniques, and increasing the number and/or the duration of dialysis tecniques are all measures able to enhance phosphorus $(\mathrm{P})$ mass removal through dialysis. However, dialytic removal does not equal the high $\mathrm{P}$ intake linked to the high dietary protein requirement of dialysis patients; hence, the use of intestinal $\mathrm{P}$ binders is mandatory to reduce $\mathrm{P}$ net intestinal absorption. Unfortunately, even a large dose of $\mathrm{P}$ binders is able to bind approximately $200-300 \mathrm{mg}$ of $\mathrm{P}$ on a daily basis, so it is evident that their efficacy is limited in the case of an uncontrolled dietary P load. Hence, limitation of dietary P intake is needed to reach the goal of neutral phosphate balance in dialysis, coupled to an adequate protein intake. To this aim, patients should be informed and educated to avoid foods that are naturally rich in phosphate and also processed food with P-containing preservatives. In addition, patients should preferentially choose food with a low P-to-protein ratio. For example, patients could choose egg white or protein from a vegetable source. Finally, boiling should be the preferred cooking procedure, because it induces food demineralization, including phosphate loss. The integrated approach outlined in this article should be actively adapted as a therapeutic alliance by clinicians, dieticians, and patients for an effective control of phosphate balance in dialysis patients.

Keywords: phosphorus, hyperphosphatemia, dialysis, phosphate binders, diet, food preservatives

\section{Introduction}

Phosphorus ( $\mathrm{P}$; atomic weight 31 Daltons) is a mineral widely present in nature as phosphate. In humans, it plays an essential role in bone metabolism, cellular signaling, nucleous, and energy metabolism. About $80 \%-85 \%$ of the total body $\mathrm{P}$ is found in bones and teeth as calcium salts; about $15 \%-20 \%$ is present in body fluids and soft tissues. It is noteworthy that circulating $\mathrm{P}$ levels, ie, the fraction measurable in clinical practice, represents only $0.1 \%$ of total body $\mathrm{P}$.

In the course of chronic kidney disease (CKD), P serum levels remain within normal limits until the advanced stages of CKD. Therefore, hyperphosphatemia must be considered a very late indicator of $\mathrm{P}$ retention. ${ }^{1}$ Instead, the increase of $\mathrm{P}$ serum levels in the individual patient, even within the normal range, may occur quite early in the course of CKD (as little as $50 \mathrm{~mL} /$ minute of glomerular filtration rate), accompanied by
Correspondence: Adamasco Cupisti Department of Clinical and Experimental Medicine, University of Pisa,

Via Roma 67, 56/26, Pisa, Italy

Tel +395099729l

Fax +3950997 287

Email adamasco.cupisti@med.unipi.it 
the increase in PTH (parathyroid hormone) and even earlier by the increase of FGF23 (fibroblastic growth factor 23). ${ }^{1}$ Following a dietary intake of $\mathrm{P}$, from the very early stages of CKD, FGF23 causes a phosphaturic response contributing to maintenance of a neutral $\mathrm{P}$ balance.

An increase in the risk of cardiovascular morbidity and mortality due to chronic hyperphosphatemia in patients undergoing hemodialysis has been demonstrated. ${ }^{2}$ Numerous studies published in the field since the late 1980s have underpinned a drastic shift in the focus of nephrologists from bone damage and extravascular calcification of the soft tissues, particularly periarticular and ocular disorders in uremic patients, ${ }^{3}$ to the cardiovascular damage related to $\mathrm{Ca}-\mathrm{P}$ metabolism abnormalities. ${ }^{4}$ This new aspect has led to a redefinition of the term "uremic osteodystrophy" to include a more comprehensive definition, namely chronic kidney disease--mineral and bone disorder (CKD-MBD). The main target of pharmacological research in the field has also moved from bone toward the cardiovascular apparatus. Prevention and correction of hyperphosphatemia is a major goal of the treatment of CKD-MBD, so special attention must be given to $\mathrm{P}$ balance. Phosphate enters the body by intestinal absorption of dietary $\mathrm{P}$; it is excreted through stools and dialysis fluids (plus urine output in patients with residual renal function). In the case of daily dialysis or long nocturnal dialysis, $\mathrm{P}$ mass removal is usually large enough to reduce the need of dietary restrictions and the use of $\mathrm{P}$ binders. This does not occur in the case of well-nourished patients on a standard three-times-a-week dialysis schedule where optimal dialysis removal, careful use of phosphate binders, and dietary $\mathrm{P}$ control are needed to optimize the control of $\mathrm{P}$ balance.

\section{Dialysis}

Despite the recent revolutionary advances in dialysis technology and the improved quality of membranes, the challenge represented by $P$ removal continues at an uneven pace when adopting conventional depuration techniques, even in the presence of high-flux convective exchanges.

Several key concepts should be kept in mind regarding dialytic removal of $\mathrm{P}$. The intradialytic output kinetics of $\mathrm{P}$ are completely different from that of urea or other small molecules for the different body volume distributions. Furthermore, mass transfer of $\mathrm{P}$ is hindered because this molecule, albeit of a low molecular weight, is coated with water particles that bind strongly to $\mathrm{P}$, thus transforming an originally small molecule into a molecule of medium dimension. Thus, its increased hydrated radius renders the passage through the pores of the dialysis membrane more difficult. Few investigations ${ }^{5,6}$ have been carried out on the structure and dynamics of hydrogen bonds between the $\mathrm{H}_{2} \mathrm{PO}_{4}{ }^{-}, \mathrm{HPO}_{4}{ }^{2-}$, and $\mathrm{PO}_{4}{ }^{3-}$. Experimental data have been published on the hydration of $\mathrm{P}$ ions employing different techniques for the purpose of investigating the ion and its surroundings; moreover, the P-oxyanion features a higher charge $\left(3^{-}\right),{ }^{5,6}$ further slowing the passage through the dialysis membrane. It is noteworthy that the three forms of $\mathrm{P}$ ions are approximately spherical, with an average van der Waals radius of more than $180 \AA$.

Almost all studies addressing $\mathrm{P}$ mass transfer are potentially affected by different biases. In fact, the majority of investigations used routine colorimetric techniques for determining $P$ levels in plasma that are not highly accurate, particularly due to the use of strong acids in routine laboratory procedures to determine the phosphomolybdate complex. ${ }^{7,8}$ These strong acids, although in contact with the plasma only very briefly, produce an immediate breakdown of proteins in plasma and/or serum with P release and overestimation of its actual levels. ${ }^{9}$

The multicompartmental distribution of $\mathrm{P}$ and its slow shift from the intracellular to the extracellular compartment and to plasma, render the postdialysis $\mathrm{P}$ rebound complex and difficult to define in terms of quantity and duration. ${ }^{9,10}$ Likewise, it is not an easy task to identify the most appropriate time for sampling, with the aim of establishing a sort of time-average $\mathrm{P}$ concentration. Undoubtedly, predialysis sampling following the long interdialysis interval is the least favorable time for assessing dietary and therapeutic compliance and for establishing a tailored-dose regimen and type of intestinal $\mathrm{P}$ binder. The timing of the serum $\mathrm{P}$ assessment may also influence the use of vitamin $\mathrm{D}$ and its derivatives. Moreover, the same predialytic levels of $\mathrm{P}$ in different conditions of acidosis make the establishment of its real mass transfer more difficult. Recently, physical exercise has been implemented during hemodialysis in an attempt to increase the removal of several molecules, including P. ${ }^{11}$

In Table 1, ranges of weekly $\mathrm{P}$ removals are reported for the different extracorporeal techniques.

Table I Ranges of phosphate removal (grams per week) by different dialysis strategies

\begin{tabular}{ll}
\hline Conventional diffusive hemodialysis, 4 hours & $2.3-2.6 \mathrm{~g}$ \\
Extended diffusive hemodialysis, $\geq 5$ hours & $3.0-3.6 \mathrm{~g}$ \\
Nocturnal hemodialysis, 8 hours & $4.5-4.9 \mathrm{~g}$ \\
Endogenous hemofiltration with reinfusion, 4 hours & $1.8-2.4 \mathrm{~g}$ \\
Postdilution hemodiafiltration, 4 hours & $3.0-3.3 \mathrm{~g}$ \\
Predilution hemofiltration (exchange volumes & \\
I.2 $\times$ body weight) & $0.9-1.5 \mathrm{~g}$ \\
Peritoneal dialysis (CAPD, $2 \mathrm{~L} \times 4 /$ day) & $2.0-2.2 \mathrm{~g}$ \\
\hline
\end{tabular}

Abbreviation: CAPD, continuous ambulatory peritoneal dialysis. 


\section{Diffusive hemodialysis techniques}

In view of the large mass of $P$ requiring removal, diffusion of $\mathrm{P}$ is insufficient both with high-efficiency membranes or with standard membranes with a low ultrafiltration coefficient, when dialysis is scheduled according to the conventional three-times-a-week regimen. Determination of the amount of $\mathrm{P}$ excreted through the different diffusive dialysis techniques is not an easy task. A series of variables may be present: patient predialysis P levels; membrane surface and permeability characteristics; session duration - currently one of the most relevant factors. With the traditional diffusive dialysis regimen (three sessions per week), $\mathrm{P}$ removal is highly variable (Table 1 ). ${ }^{12}$ Thus, in a patient consuming a normal protein diet of $1.2 \mathrm{~g} / \mathrm{kg} /$ day, the need for intestinal $\mathrm{P}$ binders is mandatory, and it is of the utmost importance to ensure that they are taken regularly as prescribed. However, in some hemodialysis patients - independently of food intake and of vitamin $\mathrm{D}$ status - $\mathrm{P}$ levels within the normal range, accompanied by normal calcium and PTH levels, may be detected..$^{13}$ This phenomenon may be due to: malfunctioning of the intestinal absorptive carrier; and/or to malabsorption phenomena; and/or nutritional disorders, often of a hereditary nature.

Even in the case of noncompliant patients, excellent results can be achieved through implementation of specific dialysis regimens. Indeed, numerous studies have demonstrated how daily ${ }^{14}$ or nocturnal dialysis ${ }^{15}$ results in an optimal control of $\mathrm{P}$ levels, at times requiring $\mathrm{P}$ supplementation to achieve normal values, ${ }^{16,17}$ or at least leading to a reduction in the use of chelating agents. The risk involved is comparable to that of the refeeding syndrome, producing an effect on blood counts and neuromuscular apparatus, which - in chronic forms - may lead to the subtle and gradual onset of damage. ${ }^{18}$ A review of the literature confirms that the most suitable means of controlling hyperphosphatemia is timerelated, indirectly demonstrating that the characteristics of $P$ removal in dialysis resemble those of a medium-sized molecule.

\section{Convective hemodialysis techniques}

Predilution hemofiltration (HF) has fallen short of expectations with regard to $P$ removal, even in the presence of optimal levels of adequacy. In convective methods, the latter is not defined on the basis of $\mathrm{Kt} / \mathrm{V}$, but it is quantified by exchange volumes capable of reaching, albeit with difficulty, 1.2 times the body weight of the patient.

A comparison carried out between HF and hemodiafiltration (HDF), at times accompanied by ultrafiltration of similar volumes to that of urea distribution, results in the gradual discontinuation of online HF procedures. Although these studies were designed to evaluate outcomes of arterial blood pressure and intrasession symptoms, no differences were observed in presession P levels, and no superiority of HF compared to HDF was observed. ${ }^{19,20}$ Since the end of the 1990s, a new hemodialytic method was introduced that employed three types of depuration: convection; adsorption by resins; and diffusion. ${ }^{21}$ An ultrafiltrate is formed by the plasma water leaving the convective filter, and it is conveyed into a cartridge containing adsorbents (polystyrenic resin), which retain various high molecular-weight toxic substances In the last step, the further purified plasma water goes into the diffusive filter. This technique, called "HFR" (HDF with endogenous reabsorption), allows the saving of useful substances (eg, vitamins) and adsorption of several cytokines. It is the only HDF that can be defined by the term "endogenous." The possibility of a favorable effect on CKD-MBD because of higher $\mathrm{P}$ depuration by ultrafiltration and adsorption was considered. HFR confirmed its high rate of elimination of cytokines but only a modest adsorption of P. ${ }^{9}$ Nevertheless, this study revealed chemical titration as the gold standard for the determination of P kinetics. The common chemicalclinical laboratory equipment, using strong acids such as sulfuric acid, produces a rapid breakdown of proteins. This accurate method of titration provides a deproteinized plasma with a weak acid (10\% trichloroacetic acid in aqueous solution), preventing breakdown of the proteins and, therefore, releasing ultrafilterable P. Subsequently, the supernatant was drawn, in which the $\mathrm{P}$ ion was made to react with a solution of ammonium molybdate with formation of a phosphomolybdic complex reduced to molybdenum blue with stannous chloride. The $\mathrm{P}$ concentration was obtained by means of a calibration curve plotted, starting from the standard. The same method was used for the dialysis fluid samples, omitting the deproteinization phase. Generally, HDF techniques show middle molecule higher removal capacity per session than diffusive procedures. These observations have been demonstrated for postdilution, ${ }^{22}$ predilution, prepostdilution, and reverse middilution methods. ${ }^{23}$ Studies aimed at investigating P mass transfer using the above methods are scarce, focusing almost entirely on the control of predialysis $\mathrm{P}$ levels. It is mandatory, however, that a congruous reinfusion dose be used, ie, higher than 18-20 L per session in postdilution HDF. Subsequent studies demonstrated a decrease in mortality and better survival rates, which could be attributed, at least in part, to an improved control of hyperphosphatemia and/or of secondary hyperparathyroidism. ${ }^{24-26}$ In pre- and 
postdilution HDF, removal efficiency is highly dependent on the exchange volume of plasma water/ultrafiltrate, which should be similar to urea distribution, corresponding to the percentage of total body water (approximately 58\%-60\%, according to subject's age). ${ }^{27} \mathrm{HDF}$ is capable of achieving removal rates exceeding 4-5 g/week, ${ }^{12}$ significantly higher than levels yielded by diffusion methods. It may be useful to consider the filtration fraction (FF), which is the ratio between ultrafiltration flow rate divided by plasma water flow rate $\left(Q_{U F} / Q_{p w i n}\right)$, to estimate the share of the larger molecule ultrafiltration output. The exact proportion is not well determined for the various types of HDF, but it can be estimated as follows: 0.5 (ultrafiltration [UF] rate $=30 \%$ of $\mathrm{Q}_{\mathrm{b}}$ ) for HDF-post; 0.7-1.25 (UF rate $=50 \%-70 \%$ of $\mathrm{Q}_{\mathrm{b}}$ ) for HDF pre- and HDF pre-post; and $\geq 1.5$ (UF rate $=100 \%$ of $\mathrm{Q}_{\mathrm{b}}$ ) for HF predilution. ${ }^{28-30}$ However, the "gold standard" for HDF for P clearance needs further studies to be identified convincingly. Today, the total time spent in dialysis is considered one of the strongest factors that influence P levels. This finding supports the use of mixed methods in daily dialysis by means of HDF. ${ }^{31}$ In fact, when daily dialysis is carried out with high-convection methods, it is possible to obtain further progress, but studies about daily HDF and/or daily HF are rare and not significant.

\section{Peritoneal dialysis}

In terms of efficacy and providing a high level of support to the peritoneum, peritoneal dialysis may be viewed as a form of long-term dialysis, combining the advantages of a better quality of life, particularly when using automated methods, with significantly lower costs.

The yield of $\mathrm{P}$ removal by peritoneal dialysis, particularly in anuric patients, is indicated as a highly important reference parameter. $P$ clearance may reach $40 \mathrm{~L} /$ week per $1.73 \mathrm{~m}^{2}$, similar to levels obtained for creatinine clearance. In this condition, the presence of phosphaturia in patients with preserved urine output plays a positive role. Total $P$ removal is strongly correlated with residual renal function parameters, but it is dissociated from peritoneal Kt/V urea and creatinine clearance. No correlation between $\mathrm{P}$ clearance and net ultrafiltration has been demonstrated. Renal and peritoneal $\mathrm{P}$ clearance rates were significantly lower in hyperphosphatemic patients. Slow transporters presented higher peritoneal $\mathrm{P}$ clearance under continuous ambulatory peritoneal dialysis (CAPD) regimens. Hyperphosphatemia has been significantly associated with a lower number of automated peritoneal dialysis (APD) cycles and a shorter duration of nocturnal treatment, with insufficient dwell time. ${ }^{32}$
In hyperphosphatemic and/or anuric patients, the decision to implement peritoneal dialysis should take into account peritoneal $\mathrm{P}$ transport characteristics and not be based solely on urea $\mathrm{Kt} / \mathrm{V}$ or peritoneal creatinine clearance. Increasing dwell times or transfer to CAPD may represent effective strategies aimed at improving $\mathrm{P}$ management in patients with inadequate $\mathrm{P}$ control on APD. Interesting considerations on a more optimal purification of $\mathrm{P}$ by peritoneal dialysis have been proposed recently and need further study, ${ }^{33}$ but if we consider a very efficient peritoneal membrane and adequate dwell time, as it happens with nocturnal APD, patients on peritoneal dialysis might achieve a better $\mathrm{P}$ control.

\section{Intestinal phosphate binders}

Intestinal $\mathrm{P}$ binders are frequently administrated to control serum $P$ levels in CKD patients, since dialysis removal and dietary restriction are often not sufficient to reach an adequate control of hyperphosphatemia.

Several $\mathrm{P}$ binders are available, acting with different mechanisms. They can be classified, according to their chemical properties as aluminum-based binders, calcium-based binders, or aluminum- and calcium-free binders. The main features of $\mathrm{P}$ binders commonly used in clinical practice are depicted in Table 2.

\section{Aluminum-based binders}

Aluminum-based binders have been largely used to control hyperphosphatemia in the past. Although very effective, their long-term use is not recommended by Kidney Disease Improving Global Outcomes (KDIGO) guidelines because of significant adverse events. In fact, aluminum accumulation has been demonstrated in bone and cerebral tissues, resulting in toxicity, known as aluminum-induced osteomalacia and encephalopathy. ${ }^{34,35}$ Moreover, a safe aluminum dose is not known for the individual patient. For these reasons, aluminum binders have been replaced by calcium-based and calcium-free binders, although in some countries they are still used in a significant number of patients. In a crosssectional study conducted between 2002-2007 in peritoneal dialysis patients, data on $\mathrm{P}$ binders' use were obtained from 369 patients. ${ }^{36}$ Among the 327 patients (88.6\%) receiving $\mathrm{P}$ binders, combination treatment was very common: $49 \%$ of patients received calcium carbonate; $35.5 \%$ sevelamer; $29.5 \%$ magnesium-containing binders; and $31.4 \%$, surprisingly, aluminum-based binders. Although the most severe cases of aluminum toxicity in the past were caused by poorly treated water in the dialysis fluid, intestinal absorption of aluminum has been proved and in specific categories (anuric patients, 
Table 2 Phosphate binders in hemodialysis patients: a summary of their main features, advantages, and adverse events

\begin{tabular}{|c|c|c|c|c|}
\hline & Chemical composition & RPBC & Advantages & $\begin{array}{l}\text { Adverse events/ } \\
\text { disadvantages }\end{array}$ \\
\hline Aluminum hydroxide & Aluminum & 1.5 & Very effective; inexpensive & Encephalopathy; adynamic \\
\hline Aluminum carbonate & & 1.7 & & $\begin{array}{l}\text { bone disease; anemia; proximal } \\
\text { myopathy }\end{array}$ \\
\hline Calcium carbonate & $\begin{array}{l}\text { Calcium carbonate, } \\
500 \mathrm{mg} \text { (elemental calcium, } \\
40 \%, 200 \mathrm{mg} \text { ) }\end{array}$ & I & Effective; inexpensive & $\begin{array}{l}\text { Gastrointestinal complications, } \\
20 \% \text { (nausea, vomiting, } \\
\text { diarrhea, constipation); } \\
\text { hypercalcemia, } 16 \% \text {; vascular } \\
\text { calcifications }\end{array}$ \\
\hline Calcium acetate (Phoslo) & $\begin{array}{l}\text { Calcium acetate, } 667 \mathrm{mg} \\
\text { (elemental calcium, } 25 \% \text {, } \\
169 \mathrm{mg} \text { ) }\end{array}$ & I & Effective; inexpensive & $\begin{array}{l}\text { Gastrointestinal complications, } \\
20 \% \text { (nausea, vomiting, } \\
\text { diarrhea, constipation); } \\
\text { hypercalcemia, I7\%; vascular } \\
\text { calcifications }\end{array}$ \\
\hline $\begin{array}{l}\text { Calcium acetate/ } \\
\text { magnesium carbonate } \\
\text { (Osvaren) }\end{array}$ & $\begin{array}{l}\text { Calcium acetate, } 435 \mathrm{mg} / \\
\text { magnesium carbonate, } 235 \mathrm{mg} \\
\text { (elemental calcium, I10 mg) }\end{array}$ & $1 / 1.3$ & $\begin{array}{l}\text { Effective; less hypercalcemia } \\
\text { than other calcium binders; } \\
\text { prevention of vascular } \\
\text { calcifications }\end{array}$ & $\begin{array}{l}\text { Gastrointestinal complications } \\
\text { (nausea, diarrhea, } 3.6 \%) ; \\
\text { muscle spasms (I.7\%); } \\
\text { hypermagnesemia }(2.1 \%)\end{array}$ \\
\hline $\begin{array}{l}\text { Sevelamer hydrochloride } \\
\text { (Renagel) }\end{array}$ & Anion-exchange resin, $800 \mathrm{mg}$ & 0.75 & $\begin{array}{l}\text { Effective; nonclassical } \\
\text { effects (reduces cholesterol } \\
\text { and uric acid, anti- } \\
\text { inflammatory action) }\end{array}$ & $\begin{array}{l}\text { Gastrointestinal complications: } \\
30 \% \text { (nausea, vomiting, } \\
\text { diarrhea, constipation); etabolic } \\
\text { acidosis; expensive }\end{array}$ \\
\hline $\begin{array}{l}\text { Sevelamer carbonate } \\
\text { (Renvela) }\end{array}$ & $\begin{array}{l}\text { Anion-exchange resin, } \\
800 / 2,400 \mathrm{mg}\end{array}$ & 0.75 & $\begin{array}{l}\text { Effective; absence/low risk } \\
\text { of metabolic acidosis versus } \\
\text { sevelamer } \mathrm{HCl}\end{array}$ & $\begin{array}{l}\text { Gastrointestinal complications } \\
\text { less than sevelamer } \mathrm{HCl} \text { : } \\
20 \% \text { (nausea, vomiting, } \\
\text { diarrhea, constipation); } \\
\text { expensive }\end{array}$ \\
\hline $\begin{array}{l}\text { Lanthanum carbonate } \\
\text { (Fosrenol or Foznol) }\end{array}$ & $\begin{array}{l}\text { Lanthanum, } \\
\text { 250/500/750/I,000 mg }\end{array}$ & 2 & $\begin{array}{l}\text { Effective; no evidence of } \\
\text { bone toxicity; improved } \\
\text { compliance by fewer daily } \\
\text { tablets }\end{array}$ & $\begin{array}{l}\text { Gastrointestinal events: } \\
\text { I0\% (nausea, vomiting, } \\
\text { diarrhea, constipation); rarely } \\
\text { headache, dizziness, } \\
\text { hypotension, myalgia; expensive }\end{array}$ \\
\hline
\end{tabular}

Notes: Frequencies of the most common side effects have been reported in percentage of affected patients, based on the available data in published controlled studies. Data for RPBC from ${ }^{38}$.

Abbreviation: RPBC, Relative Phosphate-Binding Coefficient.

children, and patient concomitantly assuming citrate, even unconsciously) it can cause adverse symptoms and even death. ${ }^{37}$

\section{Calcium-based phosphate binders}

Introduced in the 1980s and widely prescribed, calcium salts are known as effective and well-tolerated intestinal $\mathrm{P}$ binders. They are available in different formulations: calcium carbonate; calcium acetate; and calcium citrate. The latter is not used in dialysis patients, because citrate can facilitate intestinal absorption of aluminum. ${ }^{34}$

Calcium acetate, which shows the same relative $\mathrm{P}$ binder coefficient as calcium carbonate, ${ }^{38}$ achieves control of hyperphosphatemia with the same efficacy, but with a lower dose of elemental calcium. ${ }^{39}$

Current guidelines suggest prescribing calcium-based binders with caution, avoiding high dosage, and paying attention to their adverse effects. In particular, calcium binders may induce a positive calcium balance, leading to PTH oversuppression, adynamic bone disease, and vascular calcifications by calcium deposition in vessels and tissues. Moreover, it has been suggested that differences in mortality may be associated with the use of calcium-based binders when compared to sevelamer, considering the potential role of coronary and aortic calcifications as predictors of mortality. Studies addressing the compared effects of calcium-based binders and sevelamer are discussed below, in the sevelamer section of this article.

The issue of the effect of calcium-based binders on mortality in hemodialysis patients was addressed in a large observational study. ${ }^{40}$ In a study on 3,603 incident dialysis patients, $77.5 \%$ used a calcium-based binder, while $22.5 \%$ did not. Baseline use of calcium-based binders was associated with an adjusted $19 \%$ lower mortality rate compared 
with nonusers. However, matching 800 exposed and nonexposed individuals on their exposure propensity score, calcium users and nonusers had similar mortality rates. No mortality differences were observed between calcium acetate and calcium carbonate users in crude, adjusted, or propensitymatched analyses. ${ }^{40}$

A more recent calcium-based formulation comprises calcium acetate and magnesium carbonate $(\mathrm{CaMg})$. In a randomized controlled study comparing $\mathrm{CaMg}$ and calcium carbonate, lower $\mathrm{P}$ and calcium levels were observed in the group of patients treated with $\mathrm{CaMg} .{ }^{41} \mathrm{CaMg}$ allowed a decrease in calcium daily intake and the avoidance of hypercalcemia; an increase of magnesium serum level was observed in patients treated with CaMg, but apparently without a clinical impact. In the CALcium acetate MAGnesium carbonate evaluation (CALMAG) study, addressing P control in 244 hemodialysis patients followed for 24 weeks, $\mathrm{CaMg}$ results were not inferior to sevelamer $\mathrm{HCl}$, without changes in ionized calcium, minimal increase of serum calcium and magnesium, and a good tolerability. ${ }^{42}$ An interesting feature of magnesium is its inhibiting effect on vascular calcifications in in-vitro and experimental models. ${ }^{43}$ Some authors observed a significant association between low serum magnesium levels and vascular calcifications in 390 hemodialysis patients. ${ }^{44}$ The role of possible magnesium accumulation in bone tissues is still uncertain.

\section{Sevelamer hydrochloride or carbonate}

Sevelamer hydrochloride $(\mathrm{HCl})$ is an anion-exchange resin, and it is the most commonly used calcium and aluminumfree $\mathrm{P}$ binder. The efficacy of this binder in reducing $\mathrm{P}$ levels is well established. ${ }^{45}$ Sevelamer can reduce the impact of calcium overload in dialysis patients, also allowing prevention of cardiovascular complications by its nonclassical pleiotropic effects. ${ }^{46}$

In the Treat to Goal Study, ${ }^{47}$ administration of sevelamer $\mathrm{HCl}$ was associated with a reduction in the progression of coronary calcification, compared with the administration of calcium-based binders. Calcium salts also caused more episodes of hypercalcemia. ${ }^{47}$ These results were not confirmed by the Calcium Acetate $\left(\right.$ PhosLo $\left.^{\circledR}\right) /$ Sevelamer (Renagel ${ }^{\circledR}$ ) Evaluation Study 2 (CARE-2) study, which also compared the use of calcium acetate and sevelamer in the hemodialysis population. ${ }^{48}$ In this study, cardiovascular calcifications progressed similarly but significantly in both treatment groups, suggesting differences in the patient population or in the experimental design, compared to the Treat to Goal study.
In the Renagel in New Dialysis (RIND) Study, ${ }^{49}$ which enrolled patients new to dialysis, use of calcium-containing $\mathrm{P}$ binders resulted in more rapid progression of coronary calcification than did the use of sevelamer $\mathrm{HCl}$ in subjects with evidence of at least mild coronary calcification. However, new hemodialysis patients with no evidence of coronary calcification did not develop new calcifications over 18 months, independent of $\mathrm{P}$ binder therapy. ${ }^{49}$

A 44-month follow-up study assessed all-cause mortality in 127 patients of the RIND study. ${ }^{50}$ Baseline coronary calcifications were a significant predictor of mortality. Mortality was borderline significantly lower in subjects randomized to sevelamer (5.3/100 patient-years) compared to those randomized to calcium-containing binders (10.6/100 patient-years). ${ }^{50}$ With the aim of confirming such relevant mortality data, a large randomized trial compared sevelamer and calcium-based binders on all-cause and cause-specific mortality (cardiovascular, infection, and other) in 2,103 prevalent hemodialysis patients. ${ }^{51}$ Overall, all-cause mortality rates and cause-specific mortality rates were not significantly different, but in a prespecified set of patients over 65 years of age, there was a significant effect of sevelamer in lowering the mortality rate. ${ }^{51}$ Hospitalization rates were a secondary outcome of the Dialysis Clinical Outcomes Revisited (DCOR) study. Multiple all-cause hospitalization rate (1.7 versus 1.9 admissions/patient-year) and hospital days (12.3 versus 13.9 days/patient-year) were lower in the sevelamer group. ${ }^{52}$

Sevelamer has pleiotropic or nonclassical effects, such as reduction of lipid serum levels and anti-inflammation activity, ${ }^{53}$ which are attractive characteristics when considering the primary drug of choice for the control of hyperphosphatemia, despite their higher cost. On the other hand, a reduced bicarbonate level can be observed when switching a patient from calcium carbonate to sevelamer $\mathrm{HCl} ;{ }^{54}$ pill burden is relevant; and poor compliance for intestinal adverse effects has been observed.

Few data about the use of calcium-based and calciumfree $\mathrm{P}$ binders are available in peritoneal dialysis patients. ${ }^{36,55}$ In a multicenter and open-label study conducted in 143 peritoneal dialysis patients, calcium acetate and sevelamer had the same efficacy and similar tolerability, but they increased serum calcium levels in calcium acetate-treated patients. ${ }^{56}$

Sevelamer carbonate is a new formulation of sevelamer. Like sevelamer $\mathrm{HCl}$, it is an anion exchange resin, where carbonate replaces chloride. It is as effective as sevelamer $\mathrm{HCl}$, but it is able to better control the acid-base status, showing less incidence of metabolic acidosis; and it is better tolerated 
than sevelamer $\mathrm{HCl}$, especially for a reduced incidence of gastrointestinal effects. ${ }^{57}$ Sevelamer carbonate is available in two formulations - tablets and powder. Powder formulation may be helpful for the elderly and pediatric populations because of easier administration, but they also contribute to improve compliance because of the higher drug content (2,400 mg), compared to the $800 \mathrm{mg}$ tablet.

\section{Lanthanum carbonate}

Lanthanum carbonate (LC) is another noncalcium, nonaluminum $\mathrm{P}$ binder, available in tablets and in a recently released oral powder formulation. Lanthanum is a trivalent metal, similar to aluminum. Its absorption is minimal in the intestine, but it is excreted by the liver rather than the kidney which minimizes its potential toxicity. Its ability to reduce $\mathrm{P}$ levels is similar to aluminum hydroxide and two times higher than calcium carbonate. ${ }^{58}$ Its presence within the intestine can determine multiple radiopaque images in abdominal X-rays. Gastrointestinal adverse events are reported as the main side effects. ${ }^{59}$

A randomized study conducted in hemodialysis populations reported good 2-year tolerability and efficacy of LC, with less incidence of hypercalcemia and improved control of PTH levels in the group of patients treated with LC, compared with patients treated with calcium binders. ${ }^{60}$ The efficacy of LC in the peritoneal dialysis population is similar to hemodialysis. ${ }^{61}$ In a more recent study, ${ }^{62}$ high doses of LC (2,250 mg/day) were effective in P control in 39 CAPD patients, leading the authors to suggest the possibility of improving nutrition and protein intake without compromising serum $\mathrm{P}$ control. ${ }^{62}$

However, long-term data on safety are still scarce, suggesting that patients treated with LC should be monitored carefully. Up to now, no evidence of bone toxicity is reported. In particular, in a multicenter randomized study conducted to evaluate the safety and efficacy of LC on bone disease, 49 patients were randomized to receive LC, and 49 patients received calcium carbonate. LC-treated dialysis patients showed no evolution to bone disease and no association with aluminum bone toxicity. ${ }^{63}$ These results were also confirmed by other authors, showing that bone deposition after 1 year of treatment with LC was low, while a slow release of LC was observed after 2 years of follow-up, without evidence of osteomalacia or any forms of bone toxicity. ${ }^{64}$

\section{Miscellanea}

Despite the widespread use of $\mathrm{P}$ binders, some patients do not achieve the target of adequate $\mathrm{P}$ levels. Limitations and side effects of traditional binders have led to the development of novel therapeutic strategies.

\section{Chitosan chewing gum}

In consideration of the elevated salivary $\mathrm{P}$ levels in dialysis patients, ${ }^{65}$ it was found that the use of a salivary P-binding chewing gum - in addition to conventional binders - could improve the management of hyperphosphatemia in patients resistant to traditional therapy. ${ }^{66}$

\section{Iron-based binders}

The role of iron-based binders derives from the observations in uremic and nonuremic rats that iron salts and complex compound (crosslinked dextran and stabilized polynuclear iron hydroxide) reduced urinary excretion of $\mathrm{P}$, suggesting a decreased intestinal P uptake. ${ }^{67}$ In a short-term study conducted in a small group of hemodialysis patients, the use of PA21 (stabilized polynuclear iron [III]-oxyhydroxide), already known for its ability to bind to iron in in-vitro study, was well-tolerated and associated with a reduction of $\mathrm{P}$ serum levels. ${ }^{68}$ Other long-term and controlled studies are necessary, but these preliminary results suggest an alternative strategy to treat hyperphosphatemia. Gastrointestinal side effects should be evaluated in larger studies.

\section{Colestilan}

This nonmetallic and noncalcium $\mathrm{P}$ binder acts as an anion exchange resin, and it is not absorbed after oral administration. Preliminary studies have demonstrated its capability to bind dietary $\mathrm{P}$ within the intestinal tract. It can also bind bile acids, reducing low-density lipoprotein (LDL) serum levels. In a recent placebo-controlled study, the efficacy of fixed doses of colestilan $(3,6,9,12$, or $15 \mathrm{~g}$ /day) were compared to placebo for the control of serum $\mathrm{P}$ in 642 dialysis patients. Colestilan was most effective at the dose of $9 \mathrm{~g}$ /day after 12 weeks of therapy, without increasing calcium serum levels. The most common adverse events were gastrointestinal (nausea, vomiting). ${ }^{69}$

\section{Nicotinamide}

This is an inhibitor of sodium-dependent $\mathrm{P}$ cotransport in the small intestine..$^{70,71}$ For these properties, it has been proposed as an alternative binder for controlling hyperphosphatemia and hyperparathyroidism without inducing hypercalcemia in hemodialysis patients.

At a mean dose of 1,080 mg/day, nicotinamide allowed control of $\mathrm{P}$ levels, also reducing LDL cholesterol and increasing HDL cholesterol. Despite some concerns regarding side 
effects (common side effects include diarrhea, drowsiness, dizziness, nausea, vomiting, headache, and flushing of the skin) determining possible patient noncompliance, nicotinamide mimics a noncalcium, nonaluminum phosphate binder with a significantly lower cost which is increasingly used in middle- to low-income countries. ${ }^{72}$ More rarely, nicotinamide can determine significant hepatotoxicity. ${ }^{73}$

\section{Cost-effectiveness of calcium-free binders}

The KDIGO guidelines recommend restricting the use of calcium-based binders in people with persistent or recurrent hypercalcemia or arterial calcification, or both. This recommendation has been challenged by the Cochrane Review $2011,{ }^{74}$ suggesting that there are insufficient data to establish the comparative superiority of novel noncalcium binding agents over calcium-containing $\mathrm{P}$ binders for patient-level outcomes, such as all-cause mortality and cardiovascular endpoints in CKD. In this review, 60 controlled studies were identified, enrolling 7,631 participants comparing $P$ binders to placebo or to other $\mathrm{P}$ binders. There was no significant reduction in all-cause mortality (ten studies; 3,079 participants) with sevelamer $\mathrm{HCl}$ compared to calcium-based agents. There was a significant reduction in $\mathrm{P}$ (16 studies; 3,126 participants) and parathyroid hormone (twelve studies; 2,551 participants) levels, but a significant increase in the risk of hypercalcemia (twelve studies; 1,144 participants) with calcium salts compared to sevelamer $\mathrm{HCl}$. There was a significant increase in the risk of adverse gastrointestinal events with sevelamer $\mathrm{HCl}$ compared to calcium salts (five studies; 498 participants). Compared with calcium-based agents, lanthanum significantly reduced-serum calcium (two studies; 122 participants), but not serum P levels. The effects of calcium acetate on biochemical endpoints were similar to those of calcium carbonate. Although methodologically flawless, this review cannot take into account specific hints derived by a careful analysis of published studies, as specified above in this article. In addition, the length of follow-up of the available studies might have been too short to show an effect of vascular calcifications on mortality and cardiovascular events. The issue of the dose of calcium-based binders is also not addressed by Navaneethan et al. ${ }^{74}$ This is particularly important, because vascular calcifications are more likely when a positive calcium balance, seen with the higher doses of calcium-based binders, occurs.

Calcium-free binders are effective and may offer additional advantages. The major issue against their widespread use is the markedly higher cost. Based on hospitalization data of the DCOR study, cost-effectiveness in sevelamer-treated versus calcium-treated patients was studied, ${ }^{75}$ evaluating Medicare total, inpatient, outpatient, skilled nursing facility, and other costs while incorporating sevelamer and calcium binder costs. Medicare costs were lower for sevelamer-treated than for calcium-treated participants, but after $\mathrm{P}$ binder costs were incorporated, costs trended lower for calcium-treated than for sevelamer-treated patients (differential $-\$ 25$ per member per month, using wholesale acquisition cost). Whether calcium-free binders are cost-effective is still an open question, but - in our view - in case of doubts, the safest option for the patient should be preferred until properly conducted studies demonstrate that high-dose calcium-based binders are harmless.

\section{Combined treatment of phosphate binders, vitamin D, and/or calcimimetics}

The combined treatment of calcium containing $\mathrm{P}$ binders and active vitamin D may induce an increase in calcium and $\mathrm{P}$ intestinal absorption, possibly leading to hypercalcemia and to more difficult control of P levels. Experimental studies have shown that paricalcitol appears to have selective action on the parathyroid vitamin D receptor, allowing it to exert beneficial effects on PTH secretion without elevating intestinal vitamin D receptor content and increasing the risk of hypercalcemia. ${ }^{76}$

The use of calcimimetics may be associated with a reduction in serum calcium (but, not necessarily, a reduction in calcium balance). After starting calcimimetic treatment for secondary hyperparathyroidism, an initial reduction of P levels might be due to P shift toward the bone, due to reduced PTH levels, rather than an effect on intestinal $P$ transport.

\section{Dietary management}

Phosphorus enters the human body through food and beverages. The intestinal absorption of $\mathrm{P}$ occurs via a cotransport mechanism for active sodium/phosphate $(\mathrm{Na} / \mathrm{Pi})$ cotransporters. About $60 \%$ of the dietary $\mathrm{P}$ intake is absorbed as inorganic $\mathrm{P}$, increasing up to $80 \%$ when concomitant high circulating levels of calcitriol exist.

Dietary $\mathrm{P}$ burden is a function of dietary food content and of food preparation. Phosphorus is introduced as a natural component of food as constituent of phosphoproteins, phospholipids, adenosine triphosphate, adenosine diphosphate, deoxyribonucleic acid, ribonucleic acid, or as inorganic $\mathrm{P}$ salts. The latter may be found in foods, and also in food 
additives that are added for commercial and technological reasons during industrial food processing. In addition, $\mathrm{P}$ content of foods can be modified by homemade food preparation or cooking.

Protein-rich foods are the main source of dietary $\mathrm{P}$ in a free mixed diet, and the amount of $\mathrm{P}$ is directly proportional to protein content. There are equations that relate $\mathrm{P}$ and protein content of mixed diets: the most known is that of Boaz and Smetana, ${ }^{77}$ whose validity was confirmed in a cohort of 260 Italian subjects $($ dietary $\mathrm{P}[\mathrm{mg}]=101.9+12.93 \times$ dietary protein in $\mathrm{g}){ }^{78}$ However, this apparently ineluctable and constant relationship between the content of $\mathrm{P}$ and protein in a diet can be modified by education and information about food choice, processing, and cooking.

As far as the $\mathrm{P}$ content in major groups of natural foods is concerned, the highest amount of $\mathrm{P}$ is found in cheese (up to $700 \mathrm{mg} / 100 \mathrm{~g}$ ); egg yolk (586 mg/100 g); meat or fish (170-290 mg/100 g); P content in legumes varies from 300 to $590 \mathrm{mg} / 100 \mathrm{~g}$; and in cereal grains from 120 to $360 \mathrm{mg} / 100$ g. $^{79}$

Phosphorus is found in foods mainly as inorganic $\mathrm{P}$, while a share of around $40 \%$ is contained in phosphoproteins and phospholipids. ${ }^{80}$ Net intestinal absorption of dietary $\mathrm{P}$ is $60 \%$ as average. Bioavailability of $\mathrm{P}$ depends on the degree of digestibility of the food, the presence of compounds that can bind $\mathrm{P}$ inhibiting its absorption (eg, calcium, magnesium, aluminum), and/or the degree of vitamin $\mathrm{D}$ receptor activation in the gastrointestinal tract.

Phosphorus in foods of animal origin is more bioavailable than that found in foods of plant origin. ${ }^{81}$ The former is present as inorganic salts or as part of organic compounds, which are cleaved by hydrolases in the intestinal tract releasing inorganic $\mathrm{P}$, which is finally absorbed. The latter is largely in the form of phytate. ${ }^{82}$ Phytates are found mainly in cereals and legumes, where they are concentrated in the seeds and fibrous parts. This is the reason why they are abundant in whole grain products and virtually absent in refined products. In humans, the phytase enzyme is not expressed, so the degradation of phytate occurs by the intestinal flora or by nonenzymatic hydrolysis reactions. ${ }^{82}$ This results in reduced bioavailability of $\mathrm{P}$ of plant origin, remaining below $50 \%$.

The positive relationship between $\mathrm{P}$ and protein content of a mixed diet represents a serious obstacle for the end stage renal disease patient. In fact, patients on dialysis must limit $P$ intake, despite an increased demand of protein supply. In other words, dialysis patients should limit P intake without reducing their protein intake..$^{79,83}$ The use of food composition tables that include data of $\mathrm{P}$ content per gram of protein may be of great benefit for both the patient and the dialysis staff, including the renal dietician. ${ }^{79,84}$ A typical example is the egg; the yolk contains most of the P (largely as phospholipids) with a small amount of protein, while the white part of the egg contains protein ( $3.7 \mathrm{~g}$ for one egg white) with a nearly absent $\mathrm{P}$ content. The egg white is, therefore, a natural source of protein of high biological value, almost free of P. So, the implementation of recipes involving the use or the addition of egg whites allows breaking the close positive relationship between protein and $\mathrm{P}$, increasing the protein intake with a negligible supply of $\mathrm{P}$.

\section{Changes of phosphorus intake by industrial processing: food preservatives}

Nowadays, food and beverages are consumed in places far away from where they were produced and/or a long period of time after their production. In any case, the product must maintain safety and taste characteristics. Hence, addition of preservatives is a technological need due to modern changes in the cycle of food production, distribution, and consumption. $^{79}$

A food additive is any substance not normally consumed as a food in itself and not normally used as a characteristic ingredient of food, intentionally added to food for a technological need in the production, processing, preparation, packing, transport, or storage of foods. Food additives may become, by themselves or as derivatives, direct or indirect components of foods.

The European Community regulations provide the obligation to report the presence of $\mathrm{P}$ salts or polyphosphates on the food label, but their amounts are not required.

Consumers can find preservatives in the food label (in the list of ingredients) as full name or by the initial "E," followed by a number that distinguishes the individual substances. ${ }^{79}$

Phosphorus is the main component of many additives (phosphoric acid, phosphates, and polyphosphates) in processed foods. The P-containing additives are used as acidity regulators (E338-E343), and as emulsifiers and thickeners (E442, E450-E452, E544-E545). They are used by food industry processing for many purposes - to extend the conservation, enhance color, enhance flavor, and retain moisture. ${ }^{79}$ It is noteworthy that $\mathrm{P}$ in preservatives is present as inorganic salts and, thus, more easily absorbed in the intestine; its intestinal tract absorption rate approaches $100 \% .{ }^{85}$

The load of $\mathrm{P}$ derived from inorganic $\mathrm{P}$ in food additives is disproportionately high, compared to naturally present $\mathrm{P}^{79,80,85,86}$ In the USA, the $\mathrm{P}$ load from P-containing 
preservatives increased significantly from an average of $470 \mathrm{mg} /$ day in 1990 to about $1,000 \mathrm{mg}$ /day for a typical American diet in the year $2000 .{ }^{87}$ Foods containing additives are generally of lower quality and lower cost, compared to the fresh product. Hence, poorer segments of the population are at the greatest risk of an extra $\mathrm{P}$ load from additives, as suggested by a recent investigation. ${ }^{88}$

\section{Changes of phosphorus intake by homemade processing: cooking}

When considering the composition of natural and processed foods, nutrient content is generally referred to as the amount of the specific nutrient per $100 \mathrm{~g}$ of edible uncooked food. However, many foods are consumed after cooking, and this can induce a different actual $\mathrm{P}$ content of the food. Among the various methods of food cooking, boiling is able to reduce $\mathrm{P}$ content of the food, as well as the content of sodium, potassium, calcium, etc, both in plant and in animal foods.

After prolonged soaking in water, a significant reduction in the $\mathrm{P}$ content occurs. The average reduction was $51 \%$ for vegetables; legumes, 48\%; meat, 38\%; flour, 70\%; and cheese, $19 \%{ }^{89}$ However, this type of procedure is poorly accepted by the patients, because it is time consuming and reduces the palatability and taste of various food preparations. Boiling is another effective method of $\mathrm{P}$ reduction. The loss of minerals is dependent on the amount of liquid used for boiling, as well as on time and degree of food shredding. Boiling meat allows a greater reduction of $\mathrm{P}$ than of protein content; ${ }^{79,90}$ hence, this procedure is another way to break the positive relationship between dietary protein and $\mathrm{P}$ intake..$^{90}$

\section{Management of dietary phosphorus in clinical practice: need for education}

In dialysis patients, diet alone is not able to control the $\mathrm{P}$ balance, because of the high protein requirement, but much can still be done to limit the dietary $\mathrm{P}$ load and to increase the efficacy of intestinal $P$ binders. Indeed, even a high dose of $\mathrm{P}$ binder agents can block the absorption of up to 200-300 mg of dietary $\mathrm{P}$, while an uncontrolled dietary $\mathrm{P}$ intake easily overcomes $1,000-1,500 \mathrm{mg}$ per day. All these considerations appear quite obvious, but they are still largely overlooked. Unfortunately, a certain degree of nihilism exists with regard to dietary and nutritional counseling. ${ }^{91}$

Hence, the need for control and restriction of effective $\mathrm{P}$ intake becomes essential to reduce the net load of $\mathrm{P}$ to the body and to allow successful P-binding therapy. Education about the sources of dietary $\mathrm{P}^{92}$ and about the procedures and choices, allowing a reduction of effective $P$ net intestinal absorption is, therefore, essential for a correct, safe, effective, and less-expensive control of $\mathrm{P}$ overload and of improved management of CKD-MBD.

Increased training and better information provided to nurses and to patients may facilitate more effective control of dietary $\mathrm{P}$, reduction of costs, and improvement of the quality of care of hemodialysis patients. ${ }^{93,94}$ This is confirmed by reports showing that dietary counseling and educational interventions were effective in reducing $\mathrm{P}$ levels in $\mathrm{CKD}$ patients with hyperphosphatemia. ${ }^{95}$

In addition, an inadequate matching of $\mathrm{P}$ binder dosage and meal $\mathrm{P}$ loading may be a cause for failure of $\mathrm{P}$ balance control. Hence, an individual self-adjustment of $\mathrm{P}$ binders' dose, in relation to estimated meal $\mathrm{P}$ content, can significantly improve the management of hyperphosphatemia. ${ }^{96}$

\section{Conclusion}

The limited availability of dialysis facilities, the lengthening of treatment times, and also the unwillingness of the patient all hamper the use of high-volume extracorporeal dialysis schedules, particularly due to logistic issues and to the higher costs involved. This, in turn, prevents an effective balance from being achieved between $\mathrm{P}$ input and $\mathrm{P}$ output in hemodialysis. Peritoneal dialysis represents a good alternative, although difficulties in $\mathrm{P}$ control are common in peritoneal dialysis patients as well. Hyperphosphatemia may be partially limited through use of HDF techniques. The application of daily dialysis and long-term dialysis protocols taking into account duration of treatment sessions is paramount in overcoming this challenge.

Using a three-times-a-week conventional dialysis regimen, the use of intestinal $\mathrm{P}$ binders is largely needed in wellnourished dialysis patients, but they have limited capacity and efficacy if dietary P load is uncontrolled. Therefore, limitation of dietary P intake is needed as well.

In a free mixed diet, the $\mathrm{P}$ content is directly related to that of proteins. Thus, protein-rich foods, which are the main source of $\mathrm{P}$, represent a huge problem for dialysis patients who need a high-protein diet. The share of intestinal absorption (about 60\% as average) is negligible for plant $\mathrm{P}$ (in form of phytate), while it is the maximum (up to 100\%) for $\mathrm{P}$ or polyphosphates contained in food additives. The latter represents a dangerous extra load of $\mathrm{P}$, because they are hardly recognized by patients and widely used in modern nutrition, especially in low-cost food.

A simple and effective approach to reduce the load of dietary $\mathrm{P}$ without reducing that of proteins is to educate 
patients avoiding foods high in $\mathrm{P}$ - such as cheese, egg yolk, nuts, and processed food containing $\mathrm{P}$ additives. In addition, they should preferentially use boiling (that allows a decrease of sodium and potassium content, too) over other methods of cooking.

The collaboration of the dietitian is essential for nutritional education, to help the patient in the choice of foods and to promote the effective adherence to dietary rules, all of which represent crucial aspects of an integrated approach to CKD-MBD.

\section{Disclosure}

The authors report no conflicts of interest in this work.

\section{References}

1. Isakova T, Wahl P, Vargas GS, et al. Fibroblast growth factor 23 is elevated before parathyroid hormone and phosphate in chronic kidney disease. Kidney Int. 2011;79(12):1370-1378.

2. Kendrick J, Chonchol M. The role of phosphorus in the development and progression of vascular calcification. Am J Kidney Dis. 2011;58(5): 826-834.

3. Alfrey AC. The role of abnormal phosphorus metabolism in the progression of chronic kidney disease and metastatic calcification. Kidney Int Suppl. 2004;(90):S13-S17.

4. Koleganova N, Piecha G, Ritz E, et al. Arterial calcification in patients with chronic kidney disease. Nephrol Dial Transplant. 2009;24(8):2488-2496.

5. Pribil AB, Hofer TS, Randolf BR, Rode BM. Structure and dynamics of phosphate ion in aqueous solution: an ab initio QMCF MD study. J Comput Chem. 2008;29(14):2330-2334.

6. Mason PE, Cruickshank JM, Neilson GW, Buchanan P. Neutron scattering studies on the hydration of phosphate ions in aqueous solutions of $\mathrm{K}_{3} \mathrm{PO}_{4}$, $\mathrm{K}_{2} \mathrm{HPO}_{4}$ and $\mathrm{KH}_{2} \mathrm{PO}_{4}$. Phys Chem Chem Phys. 2003;5: 4686-4690.

7. Barutçuoglu B, Parildar Z, Mutaf 1, Habif S, Bayindir O. Spuriously elevated inorganic phosphate level in a multiple myeloma patient. Clin Lab Haematol. 2003;25(4):271-274.

8. Cohen AM, Magazanik A, van-der Liin E, Shaked P, Levinsky H. Pseudohyperphosphataemia incidence in an automatic analyzer. Eur J Clin Chem Clin Biochem. 1994;32(7):559-561.

9. Bolasco P, Ghezzi PM, Ferrara R, et al; Ichnusa Sardinian Polycentric Study on HFR On-Line. New method for phosphate kinetics estimation during hemodialysis and on-line hemodiafiltration with endogenous reinfusion. Blood Purif. 2006;24(3):301-308.

10. Spalding EM, Chamney PW, Farrington K. Phosphate kinetics during hemodialysis: Evidence for biphasic regulation. Kidney Int. 2002;61(2):655-667.

11. Maheshwari V, Samavedham L, Rangaiah GP, et al. Comparison of toxin removal outcomes in online hemodiafiltration and intra-dialytic exercise in high-flux hemodialysis: a prospective randomized open-label clinical study protocol. BMC Nephrol. 2012;13(1):156.

12. Lornoy W, De Meester J, Becaus I, Billiouw JM, Van Malderen PA, Van Pottelberge M. Impact of convective flow on phosphorus removal in maintenance hemodialysis patients. J Ren Nutr. 2006;16(1): 47-53.

13. Albalate M, Gruss E, Hernández J, Caramelo C. Hypophosphatemia in dialysis units. Nefrologia. 2003;23(3):252-256. Spanish [with English abstract].

14. Daugirdas JT, Chertow GM, Larive B, et al; Frequent Hemodialysis Network (FHN) Trial Group. Effects of frequent hemodialysis on measures of CKD mineral and bone disorder. J Am Soc Nephrol. 2012;23(4):727-738.
15. Rocco MV, Lockridge RS Jr, Beck GJ, et al; Frequent Hemodialysis Network Trial Group; The effects of frequent nocturnal home hemodialysis: the Frequent Hemodialysis Network Nocturnal Trial. Kidney Int. 2011;80(10):1080-1091.

16. Pierratos A, Ouwendyk M, Francoeur R, et al. Nocturnal hemodialysis: three-year experience. J Am Soc Nephrol. 1998;9(5):859-868.

17. Fouque D, McKenzie J, de Mutsert R, et al; Renilon Multicentre Trial Study Group. Use of a renal-specific oral supplement by haemodialysis patients with low protein intake does not increase the need for phosphate binders and may prevent a decline in nutritional status and quality of life. Nephrol Dial Transplant. 2008;23(9):2902-2910.

18. Mehanna HM, Moledina J, Travis J. Refeeding syndrome: what it is, and how to prevent and treat it. BMJ. 2008;336(7659):1495-1498.

19. Altieri P, Sorba G, Bolasco P, et al; Second Sardinian Multicentre Study. Predilution haemofiltration, the Second Sardinian Multicentre Study: comparisons between haemofiltration and haemodialysis during identical Kt/V and session times in a long-term cross-over study. Nephrol Dial Transplant. 2001;16(6):1207-1213.

20. Locatelli F, Altieri P, Andrulli S, et al. Hemofiltration and hemodiafiltration reduce intradialytic hypotension in ESRD. J Am Soc Nephrol. 2010;21(10):1798-1807.

21. de Francisco AL, Botella J, Escallada R, et al. Haemodiafiltration with sorbent-regenerated ultrafiltrate as replacement fluid: a multicenter study. Nephrol Dial Transplant. 1997;12(3):528-534.

22. Penne EL, van der Weerd NC, van den Dorpel MA, et al; CONTRAST Investigators. Short-term effects of online hemodiafiltration on phosphate control: a result from the randomized controlled Convective Transport Study (CONTRAST). Am J Kidney Dis. 2010;55(1):77-87.

23. Susantitaphong P, Tiranathanagul K, Katavetin P, et al. Efficacy comparison between simple mixed-dilution and simple mid-dilution on-line hemodiafiltration techniques: a crossover study. Artif Organs. 2012;36(12):1059-1065.

24. Canaud B, Bragg-Gresham JL, Marshall MR, et al. Mortality risk for patients receiving hemodiafiltration versus hemodialysis: European results from the DOPPS. Kidney Int. 2006;69(11):2087-2093.

25. Canaud B, Lévesque R, Krieter D, et al. On-line hemodiafiltration as routine treatment of end-stage renal failure: why pre- or mixed dilution mode is necessary in on-line hemodiafiltration today? Blood Purif. 2004;22(Suppl 2):40-48.

26. Maduell F, Moreso F, Pons M, et al; ESHOL Study Group. High-efficiency postdilution online hemodiafiltration reduces all-cause mortality in hemodialysis patients. J Am Soc Nephrol. 2013;24(3):487-497.

27. Altieri P, Sorba G, Bolasco P, et al; Sardinian Study Group on Hemofiltration On-line. Comparison between hemofiltration and hemodiafiltration in a long-term prospective cross-over study. J Nephrol. 2004;17(3):414- 422.

28. Bosch JP, Geronemus R, Glabman S, Lysaght M, Kahn T, von Albertini B. High flux hemofiltration. Artif Organs. 1978;2(4):339-342.

29. Drukker W, Parsons FM, Maher JF, editors. Replacement of Renal Function by Dialysis: A textbook of dialysis. Second, revised and enlarged edition. Springer Netherlands; 1983.

30. Blankestijn PJ. Haemodiafiltration: becoming the new standard? Nephrol Dial Transplant. 2013;28(1):1-2.

31. Maduell F, Navarro V, Torregrosa E, et al. Change from three times a week on-line hemodiafiltration to short daily on-line hemodiafiltration. Kidney Int. 2003;64(1):305-313.

32. Bernardo AP, Contesse SA, Bajo MA, et al. Peritoneal membrane phosphate transport status: a cornerstone in phosphate handling in peritoneal dialysis. Clin J Am Soc Nephrol. 2011;6(3):591-597.

33. Botelho C, Rodrigues A, Oliveira JC, Cabrita A. Peritoneal phosphate removal varies by peritoneal dialysis regimen: an underestimated parameter of phosphate control. J Nephrol. 2013;26(1):183-190.

34. Alfrey AC. Aluminum toxicity in patients with chronic renal failure. Ther Drug Monit. 1993;15(6):593-597.

35. Kidney Disease: Improving Global Outcomes (KDIGO) CKD-MBD Work Group. KDIGO clinical practice guideline for the diagnosis, evaluation, prevention, and treatment of Chronic Kidney Disease-Mineral and Bone Disorder (CKD-MBD). Kidney Int Suppl. 2009;113:S1-S130. 
36. Gallieni M, Caputo F, Filippini A, et al; ROCK-PD Study Investigators. Prevalence and progression of cardiovascular calcifications in peritoneal dialysis patients: A prospective study. Bone. 2012;51(3):332-337.

37. Kirschbaum BB, Schoolwerth AC. Acute aluminum toxicity associated with oral citrate and aluminum-containing antacids. Am J Med Sci. 1989;297(1):9-11.

38. Daugirdas JT, Finn WF, Emmett M, Chertow GM; Frequent Hemodialysis Network Trial Group. The phosphate binder equivalent dose. Semin Dial. 2011;24(1):41-49.

39. Almirall J, Veciana L, Llibre J. Calcium acetate versus calcium carbonate for the control of serum phosphorus in hemodialysis patients. Am J Nephrol. 1994;14(3):192-196.

40. Winkelmayer WC, Liu J, Kestenbaum B. Comparative effectiveness of calcium-containing phosphate binders in incident US dialysis patients. Clin J Am Soc Nephrol. 2011;6(1):175-183.

41. Deuber HJ. Long-term efficacy and safety of an oral phosphate binder containing both calcium acetate and magnesium carbonate in hemodialysis patients. Nieren-und Hochdruckkrankheiten. 2004;33(8):403-408.

42. de Francisco AL, Leidig M, Covic AC, et al. Evaluation of calcium acetate/magnesium carbonate as a phosphate binder compared with sevelamer hydrochloride in haemodialysis patients: a controlled randomized study (CALMAG study) assessing efficacy and tolerability. Nephol Dial Transplant. 2010;25(11):3707-3717.

43. Kircelli F, Peter ME, Sevinc Ok E, et al. Magnesium reduces calcification in bovine vascular smooth muscle cells in a dose-dependent manner. Nephrol Dial Transplant. 2012;27(2):514-521.

44. Ishimura E, Okuno S, Kitatani K, et al. Significant association between the presence of peripheral vascular calcification and lower serum magnesium in hemodialysis patients. Clin Nephrol. 2007;68(4):222-227.

45. Raggi P, Vukicevic S, Moysés RM, Wesseling K, Spiegel DM. Ten-year experience with sevelamer and calcium salts as phosphate binders. Clin J Am Soc Nephrol. 2010;5(Suppl 1):S31-S40.

46. Cozzolino M, Rizzo MA, Stucchi A, Cusi D, Gallieni M. Sevelamer for hyperphosphataemia in kidney failure: controversy and perspective. Ther Adv Chronic Dis. 2012;3(2):59-68.

47. Chertow GM, Burke SK, Raggi P; Treat to Goal Working Group. Sevelamer attenuates the progression of coronary and aortic calcification in hemodialysis patients. Kidney Int. 2002;62(1):245-252.

48. Qunibi W, Moustafa M, Muenz LR, et al; CARE-2 Investigators. A 1-year randomized trial of calcium acetate versus sevelamer on progression of coronary artery calcification in hemodialysis patients with comparable lipid control: the Calcium Acetate Renagel Evaluation-2 (CARE-2) study. Am J Kidney Dis. 2008;51(6):952-965.

49. Block GA, Spiegel DM, Ehrlich J, et al. Effects of sevelamer and calcium on coronary artery calcification in patients new to hemodialysis. Kidney Int. 2005;68(4):1815-1824.

50. Block GA, Raggi P, Bellasi A, Kooienga L, Spiegel DM. Mortality effect of coronary calcification and phosphate binder choice in incident hemodialysis patients. Kidney Int. 2007;71(5):438-444.

51. Suki WN, Zabaneh R, Cangiano JL, et al. Effects of sevelamer and calcium-based phosphate binders on mortality in hemodialysis patients. Kidney Int. 2007;72(9):1130-1137.

52. St Peter WL, Liu J, Weinhandl E, Fan Q. A comparison of sevelamer and calcium-based phosphate binders on mortality, hospitalization, and morbidity in hemodialysis: a secondary analysis of the Dialysis Clinical Outcomes Revisited (DCOR) randomized trial using claims data. Am J Kidney Dis. 2008;51(3):445-454.

53. Ferramosca E, Burke S, Chasan-Taber S, Ratti C, Chertow GM, Raggi P. Potential antiatherogenic and anti-inflammatory properties of sevelamer in maintenance hemodialysis patients. Am Heart $J$. 2005;149(5):820-825.

54. Gallieni M, Cozzolino M, Brancaccio D. Transient decrease of serum bicarbonate levels with Sevelamer hydrochloride as the phosphate binder. Kidney Int. 2000;57(4):1776-1777.

55. Cozzolino M, Stucchi A, Rizzo MA, et al. Phosphate control in peritoneal dialysis. Contrib Nephrol. 2012;178:116-123.
56. Evenepoel P, Selgas R, Caputo F, et al. Efficacy and safety of sevelamer hydrochloride and calcium acetate in patients on peritoneal dialysis. Nephrol Dial Transplant. 2009;24(1):278-285.

57. Pai AB, Shepler BM. Comparison of sevelamer hydrochloride and sevelamer carbonate: risk of metabolic acidosis and clinical implications. Pharmacotherapy. 2009;29(5):554-561.

58. Albaaj F, Hutchison AJ. Lanthanum carbonate for the treatment of hyperphosphataemia in renal failure and dialysis patients. Expert Opin Pharmacother. 2005;6(2):319-328.

59. Curran MP, Robinson DM. Lanthanum carbonate: a review of its use in lowering serum phosphate in patients with end-stage renal disease. Drugs. 2009;69(16):2339-2349.

60. Finn WF; SPD 405-307 Lanthanum Study Group. Lanthanum carbonate versus standard therapy for the treatment of hyperphosphatemia: safety and efficacy in chronic maintenance hemodialysis patients. Clin Nephrol. 2006;65(3):191-202.

61. Al-Baaj F, Speake M, Hutchison AJ. Control of serum phosphate by oral lanthanum carbonate in patients undergoing haemodialysis and continuous ambulatory peritoneal dialysis in a short-term, placebocontrolled study. Nephrol Dial Transplant. 2005;20(4):775-782.

62. Hutchison AJ, Gill M, Copley JB, Poole L, Wilson RJ. Lanthanum carbonate versus placebo for management of hyperphosphatemia in patients undergoing peritoneal dialysis: a subgroup analysis of a phase 2 randomized controlled study of dialysis patients. BMC Nephrol. 2013;14:40.

63. D'Haese PC, Spasovski GB, Sikole A, et al. A multicenter study on the effects of lanthanum carbonate (Fosrenol) and calcium carbonate on renal bone disease in dialysis patients. Kidney Int Suppl. 2003;85: S73-S78.

64. Spasovski GB, Sikole A, Gelev S, et al. Evolution of bone and plasma concentration of lanthanum in dialysis patients before, during 1 year of treatment with lanthanum carbonate and after 2 years of follow-up. Nephrol Dial Transplant. 2006;21(8):2217-2224.

65. Savica V, Calò LA, Santoro D, et al. Salivary glands: a new player in phosphorus metabolism. J Ren Nutr. 2011;21(1):39-42.

66. Savica V, Calò LA, Monardo P, et al. Salivary phosphate-binding chewing gum reduces hyperphosphatemia in dialysis patients. $J$ Am Soc Nephrol. 2009;20(3):639-644.

67. Hergesell O, Ritz E. Phosphate binders on iron base: a new perspective? Kidney Int Suppl. 1999;73:S42-S45.

68. Geisser P, Philipp E. PA21: a novel phosphate binder for the treatment of hyperphosphatemia in chronic kidney disease. Clin Nephrol. 2010;74(1):4-11.

69. Locatelli F, Dimkovic N, Spasovski G. Evaluation of colestilan in chronic kidney disease dialysis patients with hyperphosphataemia and dyslipidaemia: a randomized, placebo-controlled, multiple fixed-dose trial. Nephrol Dial Transplant. 2013;28(7):1874-1888.

70. Eto N, Miyata Y, Ohno H, Yamashita T. Nicotinamide prevents the development of hyperphosphataemia by suppressing intestinal sodiumdependent phosphate transporter in rats with adenine-induced renal failure. Nephrol Dial Transplant. 2005;20(7):1378-1384.

71. Takahashi Y, Tanaka A, Nakamura T, et al. Nicotinamide suppresses hyperphosphatemia in hemodialysis patients. Kidney Int. 2004;65(3): 1099-1104.

72. Vasantha J, Soundararajan P, Vanitharani N, et al. Safety and efficacy of nicotinamide in the management of hyperphosphatemia in patients on hemodialysis. Indian J Nephrol. 2011;21(4):245-249.

73. Knip M, Douek IF, Moore WP, et al; European Nicotinamide Diabetes Intervention Trial Group. Safety of high-dose nicotinamide: a review. Diabetologia. 2000;43(11):1337-1345.

74. Navaneethan SD, Palmer SC, Vecchio M, Craig JC, Elder GJ, Strippoli GF. Phosphate binders for preventing and treating bone disease in chronic kidney disease patients [review]. Cochrane Database Syst Rev. 2011;2:CD006023.

75. St Peter WL, Fan Q, Weinhandl E, Liu J. Economic evaluation of sevelamer versus calcium-based phosphate binders in hemodialysis patients: a secondary analysis using centers for Medicare and Medicaid services data. Clin J Am Soc Nephrol. 2009;4(12):1954-1961. 
76. Takahashi F, Finch JL, Denda M, Dusso AS, Brown AJ, Slatopolsky E. A new analog of 1,25-(OH)2D3, 19-NOR-1,25-(OH)2D2, suppresses serum PTH and parathyroid gland growth in uremic rats without elevation of intestinal vitamin D receptor content. Am J Kidney Dis. 1997;30(1):105-112.

77. Boaz M, Smetana S. Regression equation predicts dietary phosphorus intake from estimate of dietary protein intake. J Am Diet Assoc. 1996;96(12):1268-1270.

78. Cupisti A, D'Alessandro C. The impact of known and unknown dietary components to phosphorus intake. G Ital Nefrol. 2011;28(3):278-288. Italian [with English abstract].

79. Cupisti A, Kalantar-Zadeh K. Management of natural and added dietary phosphorus burden in kidney disease. Semin Nephrol. 2013;33(2):180-190.

80. Cupisti A, Benini O, Ferretti V, Gianfaldoni D, Kalantar-Zadeh K. Novel differential measurement of natural and added phosphorus in cooked ham with or without preservatives. J Ren Nutr. 2012;22(6):533-540.

81. Moe SM, Zidehsarai MP, Chambers MA, et al. Vegetarian compared with meat dietary protein source and phosphorus homeostasis in chronic kidney disease. Clin J Am Soc Nephrol. 2011;6(2):257-264.

82. Bohn L, Meyer AS, Rasmussen SK. Phytate: impact on environment and human nutrition. A challenge for molecular breeding. J Zhejiang Univ Sci B. 2008;9(3):165-191.

83. Fouque D, Vennegoor M, ter Wee P, et al. EBPG guideline on nutrition. Nephrol Dial Transplant. 2007;22(Supp1 2):ii45-ii87.

84. Cupisti A, Morelli E, D’Alessandro C, Lupetti S, Barsotti G. Phosphate control in chronic uremia: don't forget diet. J Nephrol. 2003;16(1):29-33.

85. Sherman RA, Mehta O. Dietary phosphorus in dialysis patients: potential impact of processed meat, poultry, and fish products as protein sources. Am J Kidney Dis. 2009;54(1):18-23.

86. Benini O, D’Alessandro C, Gianfaldoni D, Cupisti A. Extra-phosphate load from food additives in commonly eaten foods: a real and insidious danger for renal patients. J Ren Nutr. 2011;21(4):303-308.
87. Karalis M, Murphy-Gutekunst L. Patient education. Enhanced foods: hidden phosphorus and sodium in foods commonly eaten. J Ren Nutr. 2006;16(1):79-81.

88. Gutiérrez OM, Anderson C, Isakova T, et al; CRIC Study Group. Low socioeconomic status associates with higher serum phosphate irrespective of race. J Am Soc Nephrol. 2010;21(11):1953-1960.

89. Jones WL. Demineralization of a wide variety of foods for the renal patient. J Ren Nutr. 2001;11(2):90-96.

90. Cupisti A, Comar F, Benini O, et al. Effect of boiling on dietary phosphate and nitrogen intake. J Ren Nutr. 2006;16(1):36-40.

91. Daugirdas JT. Proposed controlled trials of phosphate reduction in CKD: which whey should we go? Kidney Int. 2010;77(10):929-930.

92. Kalantar-Zadeh K, Gutekunst L, Mehrotra R, et al. Understanding sources of dietary phosphorus in the treatment of patients with chronic kidney disease. Clin J Am Soc Nephrol. 2010;5(3):519-530.

93. Cupisti A, D’Alessandro C, Baldi R, Barsotti G. Dietary habits and counseling focused on phosphate intake in hemodialysis patients with hyperphosphatemia. J Ren Nutr. 2004;14(4):220-225.

94. Cupisti A, Ferretti V, D'Alessandro C, et al. Nutritional knowledge in hemodialysis patients and nurses: focus on phosphorus. J Ren Nutr. 2012;22(6):541-546.

95. Caldeira D, Amaral T, David C, Sampaio C. Educational strategies to reduce serum phosphorus in hyperphosphatemic patients with chronic kidney disease: systematic review with meta-analysis. J Ren Nutr. 2011;21(4):285-294.

96. Ahlenstiel T, Pape L, Ehrich JH, Kuhlmann MK. Self-adjustment of phosphate binder dose to meal phosphorus content improves management of hyperphosphataemia in children with chronic kidney disease. Nephrol Dial Transplant. 2010;25(10):3241-3249.

\section{Publish your work in this journal}

The International Journal of Nephrology and Renovascular Disease is an international, peer-reviewed open-access journal focusing on the pathophysiology of the kidney and vascular supply. Epidemiology, screening, diagnosis, and treatment interventions are covered as well as basic science, biochemical and immunological studies. The journal welcomes

\section{Dovepress}

original research, clinical studies, reviews \& evaluations, expert opinion and commentary, case reports and extended reports. The manuscript management system is completely online and includes a very quick and fair peerreview system, which is all easy to use. Visit http://www.dovepress.com/ testimonials.php to read real quotes from published authors 